\title{
Práticas (não) hegemônicas em saúde: uma análise a partir dos Estudos Culturais
}

\section{Practices (not) hegemonic in health: an analysis from the Cultural Studies}

\author{
Camila Luzia Mallmann ${ }^{1}$, Cristianne Maria Famer Rocha ${ }^{2}$
}

Resumo

Temos como tema as práticas biomédicas (hegemônicas) e Práticas Integrativas e Complementares em Saúde (não hegemônicas), que estão presentes no contexto do Sistema Único de Saúde brasileiro. O objetivo é refletir sobre tensionamentos entre as práticas biomédicas e esse conjunto de práticas não hegemônicas que emergem culturalmente e no campo da saúde, a partir das lentes analíticas dos Estudos Culturais. Como percurso metodológico, realizou-se uma breve apresentação do tema e, posteriormente, uma conversa teórica com autores pós-estruturalistas que abordam as temáticas em questão a partir de aspectos da cultura, com o uso da pesquisa exploratória qualitativa. Esse estudo fortaleceu a importância de pensarmos a produção de saúde como algo criado, construído em cada tempo/ lugar/contexto, bem como da importância de se pensar que, mesmo que modelos teóricos busquem delimitações, o que encontramos enquanto cuidados de saúde são práticas borradas, ou seja, o consumo cultural da saúde é amorfo e seus significados são construídos por quem os consomem.

Palavras-chave: Sistema Único de Saúde. Práticas biomédicas. Práticas integrativas e complementares. Estudos culturais.

\begin{abstract}
We have theme biomedical practices (hegemonic) and Integrative and Complementary Practices in Health (non-hegemonic), which are present in the context of the Unified Brazilian Health. The aim is to reflect on tensions between biomedical practices and this set of non-hegemonic practices that emerge culturally and in health, from the analytical lens of cultural studies. As a methodological course, a brief presentation of the subject was carried out and, later, a theoretical conversation with poststructuralist authors that approach the themes in question from aspects of culture, with the use of qualitative exploratory research. This study reinforced the importance of thinking about the health of production as something created, built in each time/place/context and the importance of thinking that even if theoretical models seek delimitations, what we find as health care are practices blurred, or cultural consumption health is amorphous and their meanings are built by those who consume.

Keywords: Primary health. Biomedical practices. Integrative and complementary practices. Cultural studies.

\footnotetext{
${ }^{1}$ Mestre do Programa de Pós-Graduação em Saúde Coletiva da Universidade Federal do Rio Grande do Sul. E-mail: clmallmann@ yahoo.com.br

2 Doutora em Educação pela Universidade Federal do Rio Grande do Sul. Pós-Doutorado junto à Organização Pan-Americana de Saúde (OPAS/OMS) e junto à Universidad Nacional de Educación a Distancia (UNED). Professora Adjunta da Universidade Federal do Rio Grande do Sul (UFRGS). E-mail: rcristianne@gmail.com
} 


\section{Sobre as Hegemônicas Práticas em Saúde}

As propostas da Reforma Sanitária Brasileira (com início em 1970) culminaram na Constituição Federal de 1988, a partir da qual temos a criação do Sistema Único de Saúde (SUS) e do conceito de Saúde Coletiva (SC) que, não dentro de suas limitações, questiona o modelo biomédico, em detrimento de um modelo de cuidado que integra as ciências sociais e humanas, a epidemiologia e o planejamento em sistemas de saúde. Ou seja, uma clínica em Saúde Coletiva tem como tentativa o agenciamento de práticas em saúde a partir das dimensões sociais, subjetivas, epidemiológicas, políticas e de gestão em saúde.

Nesse sentido, teóricos da Saúde Coletiva vêm contribuindo a partir do final da década de 80 , para pensarmos que as práticas em saúde podem se desenvolver sob diversas perspectivas, dependendo dos atores envolvidos, ou seja, essas práticas podem estar pautadas no paradigma biomecânico, no paradigma vitalista, em saberes populares (indígenas, africanos, por exemplo), em práticas corporais, expressivas (arte, canto, dança e entre outras) (LUZ; BARROS, 2012). Compondo com essa lógica, em 2002 a Organización Mundial De La Salud - OMS (2002) passa a incentivar o desenvolvimento de estudos e práticas sobre as medicinas tradicionais e o uso das mesmas na Atenção Primária em Saúde (APS). E em 2006 teremos, no Brasil, a criação da Política Nacional de Práticas Integrativas e Complementares (PNPIC) que passa a ser amplamente discutida e incentivada a partir de 2014, quase 10 anos depois de sua criação como política pública (BRASIL, 2006).

O modelo hegemônico nas práticas de saúde do SUS e no setor privado é o biomédico - alicerçado nas biociências e na exclusão de análises de cunho biopsicossocial (MARCO, 2006) - e teve seu crescimento e desenvolvimento pautado por meio de alegações matemáticas. No que se refere às concepções de corpo e seu funcionamento, até então se entendia que era necessário dar atenção ao todo e à combinação harmoniosa das partes, e, a partir da entrada deste método na formação e prática em saúde, passa-se a introduzir um modelo mecânico em que as partes (engrenagens) devem ser analisadas (BARROS, 2002).

A perspectiva biomédica é baseada em Descartes (2001), que definiu quatro principais regras que abordam, em sua essência, a necessidade de comprovação exata para que a verdade seja identificada, pois do contrário o autor acredita que seriam precipitações e preconceitos. A $1^{\text {a }}$ regra é que nada pode ser aceito como verdade sem evidências, a $2^{\text {a }}$ regra é fragmentar o objeto em quantas partes forem possíveis, a $3^{\mathrm{a}}$ regra é conduzir o pensamento em relação aos objetos do conhecimento do mais simples para o mais complexo e a $4^{\mathrm{a}}$ regra é se certificar, por meio da revisão, que nada foi omitido (DESCARTES, 2001). Este modelo foi aplicado ao campo das ciências biológicas, para fortalecer que as partes recebem grande prestígio, inclusive sendo atreladas a essa metodologia cartesiana (adjetivo que se refere a Descartes). Nessa lógica, as especializações (mínimas frações possíveis) tomam sentido enquanto ciência analítica, que prevê que a soma das partes é capaz de constituir o todo. A concepção de corpo, saúde e doença tem uma mudança importante, já que instaura uma analogia das mesmas enquanto uma máquina capaz de ser compreendida a partir dos seus mecanismos de funcionamento.

Com a manutenção do paradigma biomédico ou curativista na saúde, mantém-se as categorizações das doenças, os processos de adoecimento e a definição dos agentes patogênicos, buscando respostas que embasam o uso de determinados medicamentos e/ou terapêuticas, ambas alicerçadas na Saúde Baseada em Evidências (SBE). Como um exemplo desta modelagem, a prática em saúde descartou em grande medida os conhecimentos milenares sobre plantas, passado de geração em geração, conhecidas por meio de terapêuticas experimentais e populares, para se produzir medicamentos comprovados cientificamente. Com 
isso, passou-se a compreender que os medicamentos estão atrelados a compreensão de eficácia e as plantas medicinais de certa insegurança e toxicidade.

A partir dos pressupostos da eficácia, palavra esta derivada do latim e que significa que algo produz o efeito desejado, o modelo biomédico refuta aquilo que não tem a definição dos resultados esperados. Nesse sentido, práticas que não tenham o reconhecimento científico são, muitas vezes, repelidas e proibidas no exercício de várias profissões. Inclusive sendo compreendidas como práticas não passíveis de comprovação pelos métodos científicos. Em relação a isso, temos como exemplo uma tradição de cuidado milenar, a medicina indígena, que Raymundo (2013, p. 223) entende que:

Seus conceitos, seu acervo de conhecimento, suas bases de crenças, foram declarados inexistentes, deixaram de ser vistos como um saber para passar a ser uma ignorância. As verdades e conhecimentos parecem ser relativos e válidos somente para a pessoa que os criou e para aquele cujos filtros culturais o permitam apropriar-se deles e assumir seu significado.

As práticas em saúde parecem seguir esta mesma dinâmica, sendo (in)validadas de acordo com aquilo que construímos enquanto possibilidades de verdades. Sabemos que existe uma hegemonia (social e mercadologicamente) do modelo biomédico, mas também há um movimento internacional de retomada de práticas culturais/ tradicionais como práticas de saúde necessárias para um cuidado integral. Essa aceitação pode resultar em outras significações entrando no jogo dos efeitos de verdade, de conhecimento, de cuidado, outras possibilidades de composição das práticas de saúde.

Nesse sentido, o artigo tem como objetivo mostrar alguns tensionamentos e complementariedades entre as práticas biomédicas e esse outro conjunto de práticas não hegemônicas que emergem no campo da saúde nacional e internacionalmente, a partir das lentes analíticas dos Estudos Culturais. Este artigo se inscreve como parte da dissertação, em andamento, intitulada: As Práticas Integrativas e Complementares em revista: uma análise da produção discursiva na mídia, pertencente ao Programa de Pós-graduação em Saúde Coletiva da Universidade Federal do Rio Grande do Sul.

Este texto parte da compreensão que os discursos que circundam em relação às práticas em saúde são heterogêneos, marcados por diversas relações de poder. Com o intuito de compreendermos algumas dessas relações, optamos por adotar a pesquisa qualitativa exploratória como ferramenta para a busca bibliográfica, pautando-nos na leitura atenta e produzindo reflexões a partir das experiências que nos constituem. As referências utilizadas fazem parte de leituras realizadas no processo de construção da dissertação e, também, por meio da busca, pela ferramenta do Google Acadêmico, de materiais que refletissem sobre os estudos da cultura, de práticas hegemônicas (biomédicas) e não hegemônicas, a partir de uma visão pós-estruturalista.

\section{Sobre as Práticas Integrativas e Complementares}

Esse conjunto de práticas sanitárias não hegemônicas, no Brasil, é chamado pela Política Nacional de Práticas Integrativas e Complementares (PICs), mas, todavia, essas práticas recebem popularmente nomes de Integrativas, Alternativas e Complementares (e entre outras possibilidades). A defesa da importância dessas práticas na constituição do cuidado em saúde está na compreensão de que por meio da harmonização do sujeito com o ambiente natural e social é possível alcançar aspectos de saúde adequados/ esperados (NASCIMENTO; NOGUEIRA; LUZ, 2012). Elas estão relacionadas a cuidados diversos da Medicina Alopática (que usa substância ativas e intervenções físicas para o tratamento) e vêm tendo um crescimento na demanda de procura e aceitação da população e dos profissionais. A indicação e o 
encaminhamento para algumas dessas formas de cuidado alternativos, no contexto do SUS, estão, ainda, fortemente associados à comprovação científica e ao reconhecimento da área biomédica em relação a elas (THIAGO; TESSER, 2011).

As Práticas Integrativas em Saúde não são, em sua maioria, um produto da medicina ocidental e nem das comprovações a partir das técnicas da biociência, pois tem bases que advém de tradições milenares, de culturas orientais e de outros fundamentos. As práticas, de variadas filosofias, racionalidades, culturas, estão ligadas a conhecimentos de diversos povos e saberes, como terapêuticas para o cuidado, manutenção e recuperação da saúde (BORGES; MADEIRA;AZEVEDO, 2011). Com objetivos mais amplos de prevenção e de promoção em saúde de forma integral. O conjunto de Práticas Integrativas em Saúde, entendidas como não hegemônicas no SUS, começaram a ter visibilidade no Brasil a partir da influência que a OMS teve (e continua tendo) no (re)direcionamento do olhar em relação às práticas envolvidas com culturas locais e cuidados milenares. Isso ocorreu a partir de recomendações aos paísesmembros, incluindo o Brasil, da necessidade de se instaurar Práticas Alternativas e Complementares na APS (ORGANIZACIÓN MUNDIAL DE LA SALUD, 2002).

A OMS (chamada na língua inglesa de World Health Organization - WHO) define estas Práticas como "a soma total de conhecimentos, habilidades e práticas baseadas nas teorias, crenças e experiências de diferentes culturas, explicáveis ou não" (WORLD HEALTH ORGANIZATION, 2000, p. 1). Essa definição tem certo impacto na construção de políticas públicas que consideram a produção de saúde como resultado de padrões advindos da SBE, por reconhecer como cuidado em saúde práticas que não tem uma explicação científica. A abertura por parte de um órgão internacional para essas diferentes possibilidades produz, de alguma forma, ressignificações nos discursos existentes acerca do que é ter ou não saúde, fazer saúde, estar com saúde e entre outros.
Segundo autores, as PICs têm por princípio propor mudanças nos modelos vigentes e refletir sobre a necessidade de "reorientar as crenças, práticas e experiências em relação à saúde; ou seja, [...] reorientar os conceitos, as formas de intervenção e o modelo de atenção à saúde e abordagem do processo saúde-doença-cuidado" (OTANI; BARROS, 2011, p. 1801). Nesse sentido, elas parecem propor um movimento ético-estéticopolítico contra-hegemônico que põe em cheque o que é compreendido como normal, habitual e convencional nos serviços de saúde.

A regulamentação destas Práticas no Brasil ocorreu em 2006, quando foi publicada a PNPIC, impulsionada pela OMS e conferências nacionais de saúde, com o intuito de garantir a integralidade na atenção à saúde e considerar a natureza política, técnica, econômica, social e cultural que estas práticas representavam no contexto do Brasil (BRASIL, 2006). Como elemento interessante dessa política, analisamos que, de uma quantidade de práticas (culturais, artísticas, populares, vitalistas) existentes no Brasil, somente cinco foram legitimadas pela política nacional, que são a Medicina Tradicional Chinesa, o Termalismo, as Plantas Medicinais e os Fitoterápicos, a Medicina Antroposófica e a Homeopatia.

Alógica de aceitação de práticas não hegemônicas (aqui nos referimos não somente as regulamentadas pela PNPIC, mas a todas as práticas relacionadas ao paradigma vitalista, saberes populares e práticas corporais) está relacionada à possibilidade de cientificar determinada práticas, a partir do aval dos profissionais da saúde e de políticas públicas elas passam a ser consumidas social, econômica, industrialmente de forma indiscriminada. Nessa dialética, a partir da possibilidade de enquadrar algumas práticas em um saber estruturado é que se determinam como verdades em saúde, já outras, por não terem essa mesma viabilidade de estruturação, estão envoltas por discursos de inoperância, impotência e inexequibilidade. Parece haver discursos que legitimam e deslegitimam a 
constituição de práticas em saúde.

Apresenta-se na instituição e disseminação das PICs, no contexto dos serviços de saúde brasileiros, outra complexidade que diz respeito a torná-las uma aposta de tratamento. Parece ser recorrente que sua eleição como terapêutica costuma ser atrelada a paciente terminais, quando as terapêuticas biomédicas já foram extrapoladas, sendo a última opção dentro do sistema, após nenhum outro tratamento dar êxito, ou, também, nem haver encaminhamentos para elas (AURELIANO, 2013).

Tesser e Sousa (2012, p. 255) acreditam que a validade científica das PICs tem um grande empecilho de efetivar-se, "dada a hegemonia da biomedicina e da ciência na sociedade e no SUS", principalmente pelas construções linguísticas que as instauram e demarcam dentro da necessidade de ter bases explicativas sobre os efeitos, indicações, contraindicações bem definidas.

Diversas são as construções a respeito dos cuidados em saúde, sendo que as significações sempre estão tecidas pela linguagem e pela cultura. Acreditamos que a saúde e as instituições que dela se ocupam se beneficiam ao serem pensadas/ analisadas com o atravessamento da cultura, podendo, em conjunto com os movimentos dos diversos grupos que compõe a sociedade, deixar-se afetar produzindo, quiçá, novos engendramentos.

\section{As Práticas em Saúde e os Estudos Culturais}

Se cultura é um espaço de relações de poder, de luta, de extravasamento, contraposição, os Estudos Culturais (EC) representam uma possibilidade de análise e compreensão da sociedade que muito pode colaborar para se pensar também o campo da saúde, tendo em vista a sua perspectiva culturalista de compreensão dos fenômenos sociais. O campo da saúde ocupa um espaço importante na dinâmica social, assim também como seus atores. Cesar (1998) destaca que a medicina, mas podemos extrapolar para outras profissões de saúde, tem "um lugar de destaque nas políticas do estado, e o médico [profissionais da saúde] passou a empenharse de tarefas mais relacionadas à dinâmica social da vida urbana, determinando-se assim uma forma de intervenção nas esferas pública e privada" (CESAR, 1998, p. 18). Nesse sentido, as características culturais de um grupo estão atreladas e alicerçadas, também, na figura construída desse campo e dos que dele fazem parte como (re)produtores das lógicas (in)corporificadas.

Os EC são interdisciplinares, engajados com um movimento político-teórico, que não tem como ideia indicar uma teoria ou metodologia definida, verdadeira, reunindo uma série de temáticas que possam ser convenientes para os EC. Um dos teóricos importantes no campo foi Stuart Hall, que aborda a cultura como central e provocadora de mudanças por meio da constituição de outros domínios, da modificação das esferas tradicionais a partir das tecnologias na indústria cultural, da cultura como uma potência para a mudança histórica e da centralidade da cultura na gênese das identidades pessoais e sociais (HALL, 1997a). Nesse sentido, incorporamos a cultura em nosso cotidiano, a partir de pequenas apropriações, que, dia-a-dia, vão se tornando práticas corriqueiras e pautando significados e valores atribuídos. Hall (1997b) aponta isso, mencionando que, ao nos expressarmos, consumimos/utilizamos coisas culturais.

Nesse sentido, consumimos diariamente certos tipos de cultura, também nos distanciamos de tantas outras. Esse mercado da produção, circulação e troca cultural tem se expandido ainda mais através das tecnologias e da revolução da informação, fazendo uso de recursos humanos, materiais e tecnológicos do mundo inteiro (HALL, 1997b), tornando acessível, a partir de uma série de características, certos tipos de produtos, enquanto que outros acabam por não circularem da mesma forma. A constituição dos recursos sejam eles materiais, humanos de cuidado no campo da saúde também estão alicerçados nesse mercado de circulação. 
Sendo a saúde um consumo cultural, que se constitui a partir dos vários discursos que compõe o campo, entendemos o quanto as significações estão atreladas a aspectos culturais, históricos, sociais, geográficos, que desempenham mecanismos de poder em relação às construções de verdade sobre o campo. Há diversas possibilidades de práticas que podemos colocar nesse rol de verdades construídas, reproduzidas e identificadas enquanto um consumo também comercializado.

Se tomarmos por análise, por exemplo, o que é mais noticiado nos telejornais, mídias impressas em relação ao SUS veremos que é, notadamente, a falta de médicos, de remédios, de procedimentos que ocupam o maior destaque, o que nos leva a pensar que a falta desses, inviabiliza a realização de práticas de saúde. Refletir sobre as verdades construídas a respeito do consumo cultural da saúde, não tem o pressuposto de tencionar para que as verdades hegemônicas sejam entendidas como equivocadas e, dessa forma, necessitam ser combatidas. Esse movimento (de reflexão) está mais ligado à necessidade de analisar como que se constituem/ como que se formam as nossas compreensões em relação ao que é saúde, como ela é alcançada, quem produz saúde e entre outros, para assim problematizar os regimes de verdade.

E esse movimento nos ajuda a pensar que a constituição dos fatos, da vida, das relações, das instituições, pode ser vista de uma maneira diferente, entendendo como nada é definido a priori, e que a linguagem tem um papel relevante nessas construções e no consumo das coisas. E nesse sentido, a linguagem e o discurso, aspectos que compõe a utilização das coisas, passam a ser compreendidos com funções:

[...] centrais na teorização social. [...] [pois] os elementos da vida social são discursiva e linguisticamente construídos. Noções como as de "verdade", "identidade" e "sujeito" passam a ser vistas como dependentes dos recursos retóricos pelos quais elas são construídas, sem correspondência com objetos que supostamente teriam uma existência externa e independente de sua representação linguística e discursiva (SILVA, 2000, p. 111, grifo do autor).

A linguagem, nessa perspectiva, é: um elemento de constituição de mundos, de sujeitos, de discursos. Deixa de ser qualificado como um elemento próprio da linguística e passa a fazer parte de todas as esferas da sociedade, presente na vida social, na cultura, nas diferentes ordens discursivas e nas produções de sentido. E é a partir dos discursos e culturas, veiculadas também pela mídia, que "modelos daquilo que significa ser homem ou mulher, bem-sucedido ou fracassado, poderoso ou impotente" (KELLNER, 2001, p. 9), saudável ou adoecido, prática de saúde ou charlatanismo, vão se constituindo, forjando e formando nossas concepções de mundo e sociedade.

Larrosa (1994) entende que os discursos não são fruto de uma coisa, conceitos e ideias, nem de sujeitos ou coletivos, poderíamos incluir também que não são criados pelos meios de informação e assim nos apresentados, eles são "condição de possibilidade tanto do mundo de coisas quanto da constituição de um falante singular ou de uma comunidade de falantes" (LARROSA, 1194, p. 63). Por isso ele (o discurso) não admite nenhuma soberania que o tome como dele possuidor. $\mathrm{O}$ que existe nos discursos é uma variedade de enunciados, nos quais estão as posições dos sujeitos, construindo e dando-lhes um lugar discursivo.

Os discursos que permeiam sobre as práticas em saúde são um produto construído pelos processos culturais, históricos, sociais, políticos e econômicos. Raymundo (2013) mostra como o campo da saúde está imbricado em nossas constituições discursivas, já que:

“[...] tanto as práticas [em saúde] quanto à atenção em saúde são fortemente influenciadas por processos culturais, históricos, sociais, políticos e econômicos. Além desses fatores, 
existem outros, de caráter mais subjetivo, que também influenciam as práticas de saúde: as crenças e a religião" (RAYMUNDO, 2013, p. 219).

Mesmo que as questões culturais estejam aqui sendo descortinadas, entendemos que os demais processos apresentados acima são intrínsecos e correlatos. O consumo cultural da saúde se dá por meio do vários enunciados que nos constituem, e, dessa forma, vamos significando os modelos como favoráveis para determinado tempo, espaço, forma em que vivemos. Há mecanismos de poder que operam de forma a manter e reforçar certos discursos. Alves (2011) entende que o saber científico, no contexto social atual, está articulado com uma grande maquinaria industrial tecnológica, e por meio da positivação dos conhecimentos, veicula suas verdades como irrefutáveis, estabelecendo-se assim como superior aos demais saberes, no que diz respeito às possibilidades de legitimidade.

Porém, essas mesmas verdades não têm qualquer regime de autoridade, já que, conforme Raymundo (2013) e Muniz (2009), as PICs (e demais práticas não hegemônicas) têm entrado por meio de arestas que pressupõe ser possível fazer discussões com alguma integração entre saberes científicos e culturais/populares. Jacques (2003), antes mesmo da criação da PNPIC, estabelece esse diálogo, a partir da análise de uma PIC e o modelo biomédico, e ressalta que é importante que a aproximação preserve os principais "requisitos dos domínios de conhecimento no âmbito de suas respectivas linguagens" (JACQUES, 2003, p. 2). Ao pensarmos enquanto produções culturais tais práticas, entendemos que, inclusive os requisitos básicos, acabam por serem borrados e já não há como enquadrar e delimitar como somente pertencente a uma ou a outra prática, já que ocorrem fusões.

Tesser e Barros (2008) falam sobre esses diferentes diálogos que operam e explica as múltiplas denominações relacionadas às Práticas
Integrativas e Complementares, nos seus vários significados possíveis e funcionais a cada discurso. Os autores compreendem que se as práticas "[...] são usadas juntas com práticas da biomedicina, são [...] complementares; quando são usadas no lugar de uma prática biomédica, [...] alternativas; e quando são usadas conjuntamente baseadas em avaliações científicas de segurança e eficácia de boa qualidade, [...] integrativas" (TESSER; BARROS, 2008, p. 916). Os efeitos de sentido (que não são definidos a priori) demarcam certas possibilidades enunciativas. Como exemplo, analisamos que, quando na criação se define que a política nacional será chamada de práticas integrativas e complementares, existe uma produção de significados atrelados a isso, e, concomitante, um determinado conjunto de práticas e/ou um modelo de saúde que se propõe a operar.

Não nos interessa aqui militar por um ideário de cuidado, mas de pensar sobre as constituições do mesmo, como elas vão se formando e entrando e se encontrando nos cenários dos sistemas de saúde. Há um movimento de entrada de outros atores fazendo parte do rol de enunciados que constituem as significações em relação a uma vida saudável, a uma forma de tratamento. Manske e Barcelos (2016) salientam que, hoje em dia, algumas revistas de circulação nacional trazem atores que não fazem parte da medicina tradicional científica e que estes auxiliam ou, inclusive, se contrapõe a ela, alguns desses são mestres de yoga, meditação, ecologia e entre outros campos. Vemos que, no campo da mídia, há possibilidades para outras representações, ainda que não tenha o mesmo efeito na prática clínica. Percebe-se, conforme Muniz (2009, p. 3), que:

[...] as fontes de informação com base bibliográfica, que sempre se apresentaram como os lugares legitimados e autorizados para as intervenções na área, parecem estar perdendo esse papel para outros órgãos de informação e cultura, especialmente, os relacionados às organizações contemporâneas. 
Muniz (2009) refere que emergem um conjunto de diferentes representações sociais em relação à aceitação de outras fontes de informações, principalmente na possibilidade de outras verdades possam aparecer em bases bibliográficas não formais. Nesse sentido, passamos a compreender que outros meios fazem parte da constituição de verdades, como espaços de lazer, religiosos, espirituais, grupos com interesses comuns, que realizam certa organização identitária. Outros atores (alicerçados em diferentes compreensões de cuidado) falam sobre assuntos que são relacionados à saúde, o que torna multifacetado os enunciados sobre uma mesma temática, e o que permite, de certa forma, outras produções de significado na constituição dos aspectos ligados a saúde/doença, enquanto diversidade cultural.

Segundo Oliveira et al. (2004), os meios de comunicação de massa têm um papel de destaque para os processos de aprendizagem dos sujeitos de uma cultura, pensando, nesse sentido, as revistas de circulação nacional, a televisão, as redes sociais e entre outros, que fazem parte diariamente dos nossos processos para adquirir experiências. Rocha (2005) refere que esses discursos produzem efeitos interessantes, que são retomados (seja por meio da fala ou escrita) em outros momentos, por diversos sujeitos, como educadores, políticos, médicos e entre outros.

Nesse rol das significações que vamos formando, Raymundo (2013) apresenta a importância de se pensar, no campo da saúde, a questão dos processos dos quais nos identificamos como geradores de certos comportamentos, que passam a influenciar diretamente as relações que estabelecemos enquanto sujeitos: usuário, profissional, gestor e, até mesmo, com determinadas condutas e práticas. A questão da identidade faz com que alguns levem em consideração diferentes dimensões do cuidado como importantes e produtoras de significado para si; outros deixam se sujeitar pelos discursos dominantes, no sentido do que se pode ou não usufruir.
Pereira, Barros e Augusto (2011) entendem que o cuidado é, na sua essência, relacional e essa forma de interação produz, também, significados e constituem identidades, sentidos e compreensões acerca da saúde e do adoecimento, e para tanto conjuga a subjetividade, na relação de cuidado, como um investimento necessário. Nesse sentido, fazemos uma relação com o que afirma Oliveira et al. (2004, p. 1316) que entende que "os sistemas de representação, ao construírem lugares que nos posicionam ou, ao proporcionarem respostas que nos possibilitam entender aquilo que somos, constroem posições de sujeito, produzem identidades".

Entendemos que o cuidado em saúde não só produz identidades como entende Pereira, Barros e Augusto (2011), mas é a partir das significações dos diversos grupos sociais, que compõem os espaços geográficos, históricos, sociais, que ele é formado, dando sentido às práticas realizadas, constituindo aquilo que tem visibilidade. Há diversas práticas possíveis no âmbito do SUS e elas podem pensadas enquanto identidades que carregam modos de pensar a vida, a saúde, sendo que a possibilidade de se fazerem atuantes, em exercício está atrelada ao processo de legitimidade de cada grupo que as reconhece. Assim como a biomedicina advém de um período histórico, a partir de pressupostos de um grupo identitário, práticas que operam com outras racionalidades estão alicerçadas em filosofias que constituem estes grupos de origem.

Independente do sentido que damos em relação ao que é um melhor cuidado em saúde, nós utilizamos, de alguma forma, seja preventiva, curativa, terapeuticamente algum modo de se fazer saúde. Como aborda Silveira e Silveira (2016) a experiência da doença (e aqui poderíamos adicionar dos cuidados anteriores a qualquer estabelecimento patológico) não deixa passar nenhuma faixa etária. $\mathrm{E}$ por vivermos essas experiências, estamos sob a ordem dos agenciamentos aos quais somos submetidos. Isso não significa que nossas experiências são limitadas a eles, pois há inúmeras possibilidades de outras práticas, outras formas de relação, outros discursos. 
Segundo Jacques (2003), foi a partir dos anos 70, no Brasil, que houve uma mudança em relação as constituições de corpo, doença e saúde. Nesse sentido,

[...] as práticas de saúde, que antes eram destinadas apenas a extinguir a doença, passaram a ser solicitadas para atender às exigências do novo modelo de bem-estar. Sistemas de tratamentos não-convencionais com ênfase na interação das dimensões física e psíquica dos indivíduos emergiram e muitos deles contribuíram para ampliar a eficácia dos tratamentos biomédicos convencionais (JACQUES, 2003, p. 2-3).

As mudanças que já estão ocorrendo no campo da saúde em relação ao que se tem legitimidade a fazer, também tem ligação com as percepções culturais sobre a saúde e doença e, logo, de seus cuidados. Essas passam pelo processo coletivo de produção de significados, trazendo novos enunciados e, a partir destes, compreensões que refletem no processo de identificação de coletivos. Entendemos aqui que as mudanças que começaram nos anos 70 e que vem se tornando mais presentes atualmente podem apontar certas tendências, mas não superar ou substituir completamente os discursos correntes (ROCHA, 2005).

Assim como Hochman, Santos e Pires-Alves (2004), entendemos que as práticas em saúde precisam ser analisadas a partir dos:

[...] diferentes espaços geográficos, períodos históricos, grupos sociais e indivíduos [que] produzem seus próprios meios de definir a etiologia, a transmissão, a terapêutica e os sentidos de uma doença. Assim, também, é um processo político, social e culturalmente contingente a transformação de uma doença ou evento biológico em um problema de saúde pública (HOCHMAN; SANTOS; PIRESALVES, 2004, p. 45).
E, só isso, já nos permite dizer que as disputas que se travam arbitrariamente em relação ao que é certo ou não, ao que é eficaz ou não, carecem de significação se não estiverem contextualizadas e relacionadas com os discursos que as permeiam.

Nesse sentido, entendemos que, para além de pensarmos as Práticas Biomédicas, as Práticas Integrativas e Complementares, e outras tantas práticas como formas de modelar ou amodelar, é importante trazer para o campo da saúde e o modelo vigente a reflexão de que são vários interesses, enunciados, conhecimentos, experiências, narrativas, percursos que podem ter voz, a partir das várias possibilidades de manifestações: heterogêneas, múltiplas, dissonantes e representativas.

Além disso, parece haver um movimento que ultrapassa as delimitações do campo da saúde, que emerge de fora para dentro, no sentido de incentivar, a partir da utilização por diferentes grupos, que práticas que são utilizadas cotidianamente de forma paralela, inclusive não sendo consideradas como terapêuticas em saúde, passam a provocar o campo da saúde para dele fazerem parte. Há que se considerar que certas modificações começam a pairar sobre os campos hegemônicos, principalmente advindo de construções sociais e culturais que desempenham essa função.

\section{Considerações Finais}

Entendemos que a importância dos Estudos Culturais está diretamente relacionada à capacidade de análise que podemos fazer a respeito do consumo das coisas culturais e da identidade da cultura. Pensando a cultura como tendo um papel importante na reflexão e análise, na constituição das coisas e de nós mesmos, da organização social, dos processos de cuidado em saúde, das práticas que são viabilizadas.

As Práticas Biomédicas e Práticas Integrativas em Saúde são uma realidade no Brasil, que tem na 
sua heterogeneidade cultural um espaço de entradas, inclusive borrando as tentativas de delimitações que certas instituições tentam estabelecer. O que parece já não ser possível de ser enquadrado e delimitado quando se trata do que os sujeitos consomem culturalmente enquanto cuidado de saúde, já que são diversos e multifacetados os percursos pelos quais se percorre quando se está a procura de saúde.

Apesar de Hochman, Santos e Pires-Alves (2004) acharem que é possível, mesmo não sendo uma tarefa simples, associar processos socioculturais e conteúdos biológicos, perguntamo-nos sobre qual seria a necessidade de enquadrarmos as coisas a partir de uma lógica normativa e de completude. $\mathrm{O}$ que nos faria voltar às premissas de que as coisas precisam estar racionalmente delimitadas. Talvez as possibilidades estejam na incompletude, na incomplementariedade, em discursos paralelos - que podem ser atravessados ou não -, mas que produzem sentido individual ou coletivo.

Poder-se-ia pensarmos em outras diversas possibilidades de análise em relação as PICs a partir de compreensões da cultura, das identidades, das relações de poder, da legitimidade e entre outros. Este estudo ainda seguirá, já que é um recorte da dissertação mencionada. Destacamos a importância de que outros estudos na área da saúde pensem sobre o quanto as práticas reproduzidas estão permeadas por verdades que entendemos como tal a partir das nossas vivências, das relações com o período histórico, espacial que nos encontramos. E, além disso, os Estudos Culturais tem importante papel na discussão em relação aos regimes de verdade, podendo ser um suporte para que estudos na área da saúde possam refletir sobre o que está em jogo na construção e prática da saúde.

\section{Referências}

ALVES, W. O espetáculo do saber: corpos, imagens e materialidades médicas. Revista EPOS, Rio de Janeiro, v. 2, n. 2, jul./dez. 2011.
AURELIANO, W. A. Terapias espirituais e complementares no tratamento do câncer: a experiência de pacientes oncológicos em Florianópolis (SC). Caderno de Saúde Coletiva, Rio de Janeiro, v. 21, n. 1, p. 18-24, mar. 2013. Disponível em: <http://www.scielo.br/scielo. php?script=sci_arttext\&pid=S1414-462X201300010000 $4 \& \operatorname{lng}=$ en\&nrm $=$ iso $>$. Acesso em: 26 out. 2016.

BARROS, J. A. C. Pensando o processo saúde doença: a que responde o modelo biomédico? Saúde \& Sociedade, São Paulo, v. 11, n. 1, p. 67-84, jul. 2002. Disponível em: $\quad<$ http://www.scielo.br/scielo.php?script=sci arttext\&pid=S0104-12902002000100008\&lng=en\&nrm $=$ iso $>$. Acesso em: 27 out. 2016.

BORGES, M. R.; MADEIRA, L. M.; AZEVEDO, V. M. G. O. As práticas integrativas e complementares na atenção à saúde da mulher: uma estratégia de humanização da assistência no Hospital Sofia Feldman. Revista Mineira de Enfermagem, Belo Horizonte, v. 15, n. 1, p. 105-113, mar. 2011. Disponível em: <http://www. sofiafeldman.org.br/wp-content/uploads/2011/08/Aspráticas-integrativas.pdf $>$. Acesso em: 20 mar. 2016.

BRASIL. Ministério da Saúde. Secretaria de Atenção à Saúde. Departamento de Atenção Básica. Política nacional de práticas integrativas e complementares no SUS - PNPIC-SUS. Brasília, 2006. Disponível em: $<$ http://bvsms.saude.gov.br/bvs/publicacoes/pnpic.pdf $>$. Acesso em: 10 maio 2015.

CÉSAR, M. R. C. A invenção da "adolescência" no discurso psicopedagógico. 1998. Dissertação (Mestrado em Educação) - Universidade Estadual de Campinas, Campinas, 1998.

DESCARTES, R. Discurso do método. Tradução de Maria Ermantina Galvão. São Paulo: Fontes, 2001.

HALL, S. A centralidade da cultura: notas sobre as revoluções de nosso tempo. Educação \& Realidade, Porto Alegre, v. 22, n. 2, p. 15-46, jul./dez. 1997a.

HALL, S. The work of representation. In: Representation: cultural representations and signifying practices. Tradução de Ricardo Uebel. London: Sage, 1997b. p. 13-71.

HOCHMAN, G.; SANTOS, P. X.; PIRES-ALVES, F. A. História, saúde e recursos humanos: análises e perspectivas. In: BARROS, A. F. R.; SANTANA, J. P.; SANTOS-NETO, P. M. Observatório de recursos humanos em saúde no Brasil: estudos e análises. Brasília: Ministério da Saúde, 2004. p. 37-50. 
JACQUES, L. M. Categorias epistemológicas e bases cientificas da medicina tradicional chinesa. 2003. Tese (Doutorado) - Universidade Federal do Rio de Janeiro, Rio de Janeiro, 2003. Disponível em: $\quad<$ http://www.academia.edu/6472425/ CATEGORIAS_EPISTEMOL\%C3\%93GICAS_E BASES_CIENT\% $\%$ C3\%8DFICAS_DA_MEDICINA_TRADICIONAL_CHINESA>. Acesso em: 26 out. 2016.

KELLNER, D. A cultura da mídia: estudos culturais: identidade e política entre o moderno e o pós-moderno. São Paulo: EDUSC, 2001.

LARROSA, J. Tecnologias do eu e educação. In: SILVA, T. T. (Org.). O sujeito da educação: estudos foucaultianos. Petrópolis: Vozes, 1994. p. 35-86.

LUZ, M. T.; BARROS, N. F. Racionalidades médicas e práticas integrativas em saúde: estudos teóricos e empíricos. Rio de Janeiro: UERJ/IMS/LAPPIS, 2012.

MANSKE, G. S.; BARCELOS, T. S. Práticas corporais medicalizantes: diagnosticando a revista vida simples. Movimento, Porto Alegre, v. 22, n. 1, p. 233-246, jan./ mar. 2016. Disponível em: <http://www.seer.ufrgs.br/ index.php/Movimento/article/view/54900>. Acesso em: 25 out. 2016.

MARCO, M. A. Do modelo biomédico ao modelo biopsicossocial: um projeto de educação permanente. Revista Brasileira de Educação Médica, Rio de Janeiro, v. 30, n. 1, p. 60-72, abr. 2006. Disponível em: <http://www. scielo.br/scielo.php? script $=$ sci_arttext\&pid $=\mathrm{S} 0100$ $55022006000100010 \& \operatorname{lng}=\mathrm{en} \& n \mathrm{nrm}=$ iso $>$. Acesso em: 26 out. 2016.

MUNIZ, S. V. A memória social sobre o envelhecimento saudável e a mediação da Comunicação. Revista ECOPós, Rio de Janeiro, v. 11, n. 2, abr. 2009. Disponível em: <https://revistas.ufrj.br/index.php/eco_pos/article/ view/992>. Acesso em: 28 out. 2016.

NASCIMENTO, M. C.; NOGUEIRA, M. I.; LUZ, M. T. Produção científica em racionalidades médicas e práticas de saúde. Cadernos de Naturologia e Terapias Complementares, Florianópolis, v. 1, n. 1, p. 13-21, 2012. Disponível em: <www.portaldeperiodicos.unisul. br/index.php/CNTC/article/view/1000/945>. Acesso em: 3 mar. 2016.

OLIVEIRA, D. L. L. C. et al. A negociação do sexo seguro na TV: discursos de gênero nas falas de agentes comunitárias de saúde do Programa Saúde da Família de Porto Alegre, Rio Grande do Sul, Brasil. Cadernos de Saúde Pública, Rio de Janeiro, v. 20, n. 5, p. 1309-1318, out. 2004. Disponível em: <http://www.scielo.br/scielo. php?script $=$ sci_arttext\&pid $=$ S0102-311X200400050002 $5 \& \operatorname{lng}=$ en\&nrm=iso $>$. Acesso em: 28 out. 2016.
ORGANIZACIÓN MUNDIAL DE LA SALUD. Estrategia de la OMS sobre medicina tradicional 2002-2005. Geneva, 2002. Disponível em: <www. dominiopublico.gov.br/download/texto/op000023.pdf $>$. Acesso em: 20 mar. 2016.

OTANI, M. A. P.; BARROS, N. F. A medicina integrativa e a construção de um novo modelo na saúde. Ciência e Saúde Coletiva, Rio de Janeiro, v. 16, n. 3, p. 1801-1811, mar. 2011. Disponível em: <http://www. scielo.br/scielo.php?script $=$ sci_arttext\&pid $=$ S1413$81232011000300016 \& \operatorname{lng}=\mathrm{en} \& \mathrm{nrm}=\mathrm{iso}>$. Acesso em: 28 out. 2016.

PEREIRA, T. T. S. O.; BARROS, M. N. S.; AUGUSTO, M. C. N. A. O cuidado em saúde: o paradigma biopsicossocial e a subjetividade em foco. Revista Mental, Barbacena, v. 9, n. 17, p. 523-536, dez. 2011. Disponível em: <http://pepsic.bvsalud.org/scielo.php?script=sci arttext\&pid=S1679-44272011000200002\&lng=pt\&nrm =iso $>$. Acesso em: 15 out. 2016.

RAYMUNDO, M. M. Interculturalidade e a conjunção de saberes que congregam a atenção em saúde. Revista Bioética, Brasília, v. 21, n. 2, p. 218-225, ago. 2013. Disponível em: <http://www. scielo.br/scielo.php?script $=$ sci_arttext\&pid $=$ S1983$80422013000200004 \& \operatorname{lng}=\mathrm{en} \& \mathrm{nrm}=\mathrm{iso}>$. Acesso em: 26 out. 2016.

ROCHA, C. M. F. A escolar na mídia: nada fora do controle. 2005. Tese (Doutorado em Educação) Universidade Federal do Rio Grande do Sul, Porto Alegre, 2005. Disponível em: <hdl.handle.net/10183/6351>. Acesso em: 1 set. 2016.

SILVA, T. T. Teoria cultural e educação: um vocabulário crítico. Belo Horizonte: Autêntica, 2000.

SILVEIRA, R. M. H.; SILVEIRA, B. R. A doença na literatura infanto-juvenil: análise de quatro obras contemporâneas. Via Atlântica, São Paulo, n. 29, p. 389406, set. 2016. Disponível em: <http://www.revistas.usp. br/viaatlantica/article/view/108001/118198>. Acesso em: 27 out. 2016 .

TESSER, C. D.; BARROS, N. F. Medicalização social e medicina alternativa e complementar: pluralização terapêutica do Sistema Único de Saúde. Revista de Saúde Pública, São Paulo, v. 42, n. 5, p. 914-920, out. 2008. Disponível em: <http:// www.scielo.br/scielo.php? script $=$ sci_arttext $\&$ pid $=$ S0034-89102008000500018 $>$. Acesso em: 26 mar. 2016. 
TESSER,C.D.;SOUSA,I.M.C.Atençãoprimária, atenção psicossocial, práticas integrativas e complementares e suas afinidades eletivas. Saúde e Sociedade, São Paulo, v. 21, n. 2, p. 336-350, 2012. Disponível em: <http:// www.scielo.br/scielo.php?script=sci_arttext\&pid $=$ S0104-12902012000200008>. Acesso em: 5 mar. 2016 .

THIAGO, S. C. S; TESSER, C. D. Percepção de médicos e enfermeiros da estratégia de saúde da família sobre terapias complementares. Revista de Saúde Pública, São Paulo, v. 45, n. 2, p. 249-257, abr. 2011. Disponível em: $\quad<$ http://www.scielo.br/scielo.php?script=sci arttext\&pid $=$ S0034-89102011000200003\&lng=en\&nrm =iso>. Acesso em: 26 mar. 2016.
WORLD HEALTH ORGANIZATION - WHO. General guidelines for methodologies on research and evaluation of traditional medicine. Geneva, 2000. Disponível em: $<$ http://apps.who.int/medicinedocs/pdf/whozip42e/ whozip42e.pdf $>$. Acesso em: 14 jan. 2016. 